\title{
El control del desarrollo de Legionella pneumophila en el sur de España
}

\author{
The control of the development of Legionella pneumophila in southern Spain
}

\author{
Enrique Gea-Izquierdo ${ }^{1}$ \\ ${ }^{1}$ Ph.D. Master en Ciencias. Cátedra de Seguridad y Salud en el Trabajo. Universidad de Málaga. Málaga, España. \\ * Estudio parcialmente realizado mediante una ayuda concedida por la Junta de Andalucía, España.
}

Señor Editor,

Conocedores de la difusión científica de 'Anales de la Facultad de Medicina', comunicamos mediante la presente carta el trabajo que realizamos sobre un importante tema de salud pública en el sur de España, que es la infección por Legionella pneumophila, trabajo en el cual analizamos el control preventivo del desarrollo de dicha bacteria según los condicionantes sanitarios españoles, con la finalidad de la mejora sanitaria sobre este tema. Como es de conocimiento general, la neumonía por Legionella pneumophila es una infección pulmonar bacteriana cuyos brotes aparecen cuando las personas inhalan aerosoles que contienen agua (por ejemplo, los procedentes de las torres de agua para refrigeración de aire acondicionado, fuentes, aspersores de riego, duchas) contaminados con la bacteria legionela. Las personas se pueden exponer a estos aerosoles en casa, lugares de trabajo, hospitales y lugares públicos. Legionella pneumophila se reproduce en circunstancias de humedad muy elevadas y es resistente a los desinfectantes; por ello, un foco habitual de infección lo constituyen las torres de refrigeración de grandes edificios.
Nuestro objetivo fue determinar el grado de control preventivo de desarrollo de la bacteria Legionella pneumophila según los condicionantes sanitarios nacionales españoles y su posible influencia en la población expuesta. Como parte de la metodología empleada se aplicó un cuestionario validado a la población y se inspeccionó las fuentes de dispersión de la bacteria en el sur de España (costa e interior de Málaga). Mediante muestreo aleatorio se inspeccionó 214 edificios de uso público, donde se ubicó 14 posibles fuentes contaminantes con riesgo de exposición poblacional.

Los resultados más importantes de nuestro estudio mostraron que $61 \%$ de la población encuestada no toma medidas preventivas al respecto de esta infección; y $38 \%$ desconoce los métodos de control adecuados. Las instalaciones de agua caliente de algunos establecimientos de salud analizados presentaron mayor control sanitario que los surtidores de agua de las unidades dentales de los mismos centros. Debido a la gran diversidad de instalaciones, los hospitales presentaron deficiencias en el mantenimiento preventivo frente a la legionelosis, ocurriendo lo contrario en los centros privados de salud. En general, el mayor riesgo se concentró en los establecimientos hoteleros y el menor riesgo en los institutos de educación secundaria. Como parte de la investigación, hallamos una asociación estadísticamente significativa entre el cumplimiento de las normas sanitarias nacionales y el tipo de edificación sin diferenciación entre propiedad pública o privada.

Comunicamos lo anterior para dar a conocer la importancia de este tema en España y promover una adecuada prevención con el mantenimiento de las torres de refrigeración y los sistemas de conducción de agua, especialmente del agua caliente sanitaria, para limitar el crecimiento y expansión de estos microorganismos.

Correspondencia:

Enrique Gea Izquierdo

Cátedra de Seguridad y Salud en el Trabajo.

Universidad de Málaga. Málaga, España.

Correo-e: enriquegea@telefonica.net 